\title{
Deposition and Characterization of CVD-Grown Ge-Sb Thin Film Device for Phase-Change Memory Application
}

\author{
C. C. Huang, B. Gholipour, K. Knight, J. Y. Ou, and D. W. Hewak \\ Optoelectronics Research Centre, University of Southampton, Southampton SO17 1BJ, UK \\ Correspondence should be addressed to C. C. Huang, cch@orc.soton.ac.uk
}

Received 15 November 2011; Accepted 5 January 2012

Academic Editor: Ram Gupta

Copyright () 2012 C. C. Huang et al. This is an open access article distributed under the Creative Commons Attribution License, which permits unrestricted use, distribution, and reproduction in any medium, provided the original work is properly cited.

Germanium antimony (Ge-Sb) thin films with tuneable compositions have been fabricated on $\mathrm{SiO}_{2} / \mathrm{Si}$, borosilicate glass, and quartz glass substrates by chemical vapour deposition (CVD). Deposition takes place at atmospheric pressure using metal chloride precursors at reaction temperatures between 750 and $875^{\circ} \mathrm{C}$. The compositions and structures of these thin films have been characterized by micro-Raman, scanning electron microscope (SEM) with energy dispersive X-ray analysis (EDX) and X-ray diffraction (XRD) techniques. A prototype Ge-Sb thin film phase-change memory device has been fabricated and reversible threshold and phase-change switching demonstrated electrically, with a threshold voltage of 2.2-2.5 V. These CVD-grown GeSb films show promise for applications such as phase-change memory and optical, electronic, and plasmonic switching.

\section{Introduction}

There is currently worldwide interest in the development of the next generation of computer memory, fuelling research in new materials which can be used to potentially store vast amounts of information. Phase-change random access memory (PCRAM) has attracted considerable interest as a candidate for the next generation of nonvolatile devices which will meet current and future needs of higher density, power consumption, and operation speed $[1,2]$. Ternary $\mathrm{Ge}_{2} \mathrm{Sb}_{2} \mathrm{Te}_{5}$ (GST) compounds are widely regarded as the most commercially viable and practical phase-change family of materials for this application. These materials are currently being trialled commercially, and processes which deposit GST films by RF sputtering are being implemented into production lines [3]. Chemical vapour deposition techniques are expected to play a role in device fabrication and recently metal organic chemical vapour deposition (MOCVD) process has been applied to deposit GST materials in submicron cell pores [4]. In addition, the atomic layer deposition (ALD) process, which uses a mixture of metal organic and metal chloride precursors, has been reported for the fabrication of GST thin films. However, the contamination of $\mathrm{O}, \mathrm{H}, \mathrm{C}$, and $\mathrm{Cl}$ atoms was reported as a consequence of the low deposition temperature [5]. There remains however many challenges [6] which include the need to control device-to-device variability and undesirable changes in the phase-change material that can be induced by the fabrication procedure. In addition the relatively long crystallization time of GST ( hundreds nanoseconds) limits the ultimate operation speed of the PCRAM device [7]. A confined cell structure where the phase-change material is formed inside a contact via is expected to be essential for the next-generation PCRAM device because it requires lower switching power [8]. This structure however requires more complex deposition of the active chalcogenide into a cell pore. We believe that CVD techniques could provide better performance and enable the production of thin films with superior quality compared to those obtained by sputtering, especially in terms of conformality, coverage, and stoichiometry control, and allows implementation of phasechange films in nanoelectronic devices. In addition, CVD deposition is well known to provide higher purity materials and provides the scope for new phase change materials with optimized properties to be deposited.

Recently, Te-free, Sb-based phase change materials doped with Ge, In, Ga, Sn, and Zn have attracted interest because of their faster crystallization speed and long-term stability [9-16]. Because undoped Sb is usually crystalline over the 


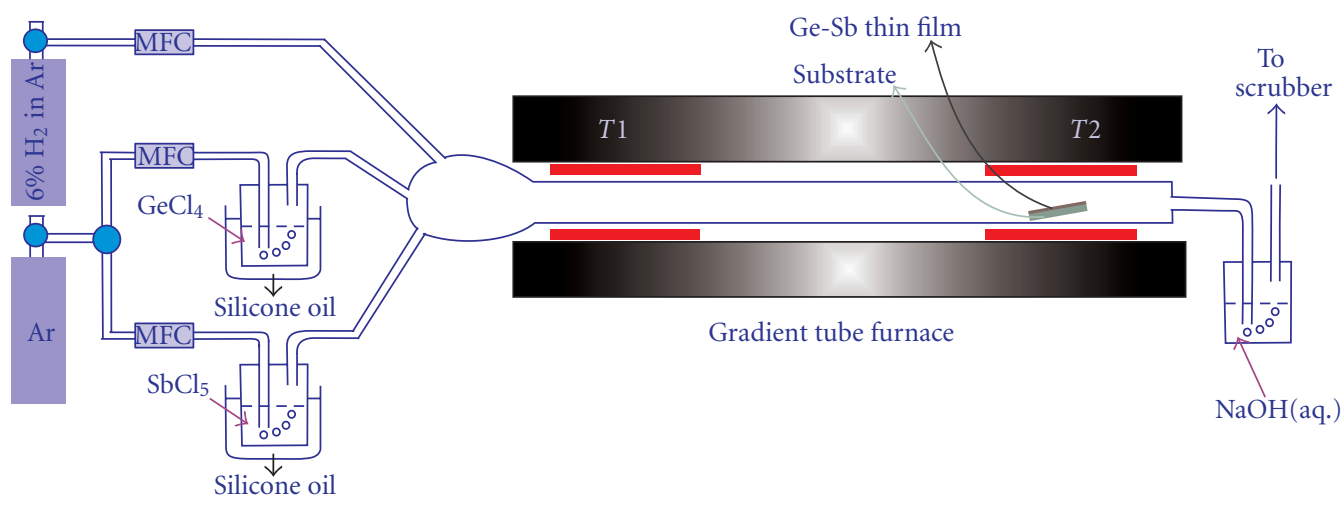

FIgURE 1: Schematic diagram of CVD system used for Ge-Sb thin film deposition.

operation temperature range of PCRAM, dopants should play an important role in enhancing the amorphous phase stability, even though it reduces the crystallization speed slightly. Among the various doped Sb-based phase change materials, the Ge-doped $\mathrm{Sb}$ alloy has been studied widely since first proposed in the 1990s. Afonso et al. demonstrated that a reversible phase change in $\mathrm{Ge}_{10} \mathrm{Sb}_{90}$ can be achieved with femto- and picosecond laser pulses $[9,10]$. Recently, Kim et al. reported the effect of the composition and microstructure on the electrical resistivity of $\mathrm{Ge}-\mathrm{Sb}$ materials deposited by cyclic plasma-enhanced CVD using a supercycle concept with metal-organic precursors [17]. For the past eight years, we have been developing the CVD technique based on metal halide precursors for the deposition of chalcogenide thin films [18-20]. In this paper, we report on the deposition of Ge-Sb thin films with tuneable compositions using atmospheric pressure CVD processes with metal chloride precursors. These Ge-Sb thin films have also been characterized by micro-Raman, SEM, EDX, and XRD techniques. In addition electrical characterization of a phase change memory device based on the eutectic Ge-Sb composition has been carried out and reversible threshold and phase change switching demonstrated.

\section{Apparatus and Experimental Methods}

The CVD apparatus we designed and built for Ge-Sb thin film deposition is shown schematically in Figure 1. A specially designed tube furnace with two individually controlled heating zones was used to produce a tailored gradient hot zone within a horizontal quartz tube. This formed a reactor with dimensions $25 \mathrm{~mm}$ O.D. $\times 750 \mathrm{~mm}$ long. The first heating zone (zone 1) upstream of the sample provided a region of sufficient temperature for the reaction of precursors to take place efficiently. The second heating zone (zone 2) was designed to keep the substrate at suitable temperature for deposition. The entire process took place at atmospheric pressure. Prior to deposition, the substrates were cleaned by acetone, isopropyl alcohol (IPA), rinsed with the deionized water, and dried in vacuum oven at $95^{\circ} \mathrm{C}$.

The reaction temperature at zone 1 was set at a fixed temperature between $750^{\circ} \mathrm{C}$ and $875^{\circ} \mathrm{C}$ with the temperature determining the ratios between $\mathrm{Ge}$ and $\mathrm{Sb}$ in the film formation. The reactive gas, $6 \% \mathrm{H}_{2}$ balanced with argon gas $\left(6 \% \mathrm{H}_{2} / \mathrm{Ar}\right)$, and the carrier argon gases for $\mathrm{GeCl}_{4}$ and $\mathrm{SbCl}_{5}$ are delivered through mass flow controllers (MFCs) at flow rates in the range of $50 \mathrm{~mL} / \mathrm{min}-250 \mathrm{~mL} / \mathrm{min}$. The substrates, located in zone 2 , were kept at $150^{\circ} \mathrm{C}$ inside gradient tube furnace throughout the deposition process. Ge-Sb thin films with tuneable compositions can be achieved by changing the flow rates of reactive gas and carrier gases of precursors or the reaction temperatures at zone 1, as shown in Figure 1. To simplify the CVD reaction, we used fixed gas flow rates of $\mathrm{GeCl}_{4}, \mathrm{SbCl}_{5}$, and $6 \% \mathrm{H}_{2} / \mathrm{Ar}$ of $50 \mathrm{~mL} / \mathrm{min}, 150 \mathrm{~mL} / \mathrm{min}$, and $200 \mathrm{~mL} / \mathrm{min}$, respectively. By simply changing the reaction temperature at zone 1, the ratio of $\mathrm{Ge}$ to $\mathrm{Sb}$ in the deposited $\mathrm{Ge}-\mathrm{Sb}$ film can be varied. In this process, $\mathrm{Sb}$ acted as the base material or host and Ge acted as the dopant in the Ge-Sb thin films. Therefore, the higher the temperature of the CVD reaction, the greater the content of germanium incorporated in the Ge-Sb thin film.

A prototype $\mathrm{Ge}-\mathrm{Sb}$ thin film phase-change memory device, as shown in Figure 2(a), has been fabricated for preliminary electrical characterization. The eutectic Ge-Sb $\left(\sim \mathrm{Ge}_{15} \mathrm{Sb}_{85}\right)$ thin film grown by CVD technique with a thickness of about $20 \mathrm{~nm}$ was deposited on the $\mathrm{SiO}_{2} / \mathrm{Si}$ substrate presputtered with a Ti-W bottom electrode slab about $500 \mathrm{~nm}$ thick. This was followed by the top Ti$\mathrm{W}$ electrode strips with the dimensions of $1.5 \mathrm{~mm}$ wide and $150 \mathrm{~nm}$ thick which were deposited on top of the CVD-grown eutectic Ge-Sb thin film. The device was then completed with a sputtered $140 \mathrm{~nm} \mathrm{ZnS}-\mathrm{SiO}_{2}$ capping layer. Among several of the devices fabricated, one was sacrificed with a diamond pen, and the multilayer structure of the edge profile was shown in Figure 2(b). This SEM image revealed the Ge-Sb thin film phase-change memory device was in a good agreement with the design in Figure 2(a).

\section{Results and Discussion}

Ge-Sb thin films with variable compositions between $14.9 \%$ and $66.9 \%$ Ge have been successfully deposited on various substrates including $\mathrm{SiO}_{2} / \mathrm{Si}$, borosilicate glass, and quartz glass. Scanning electron microscopy (SEM) technique has 


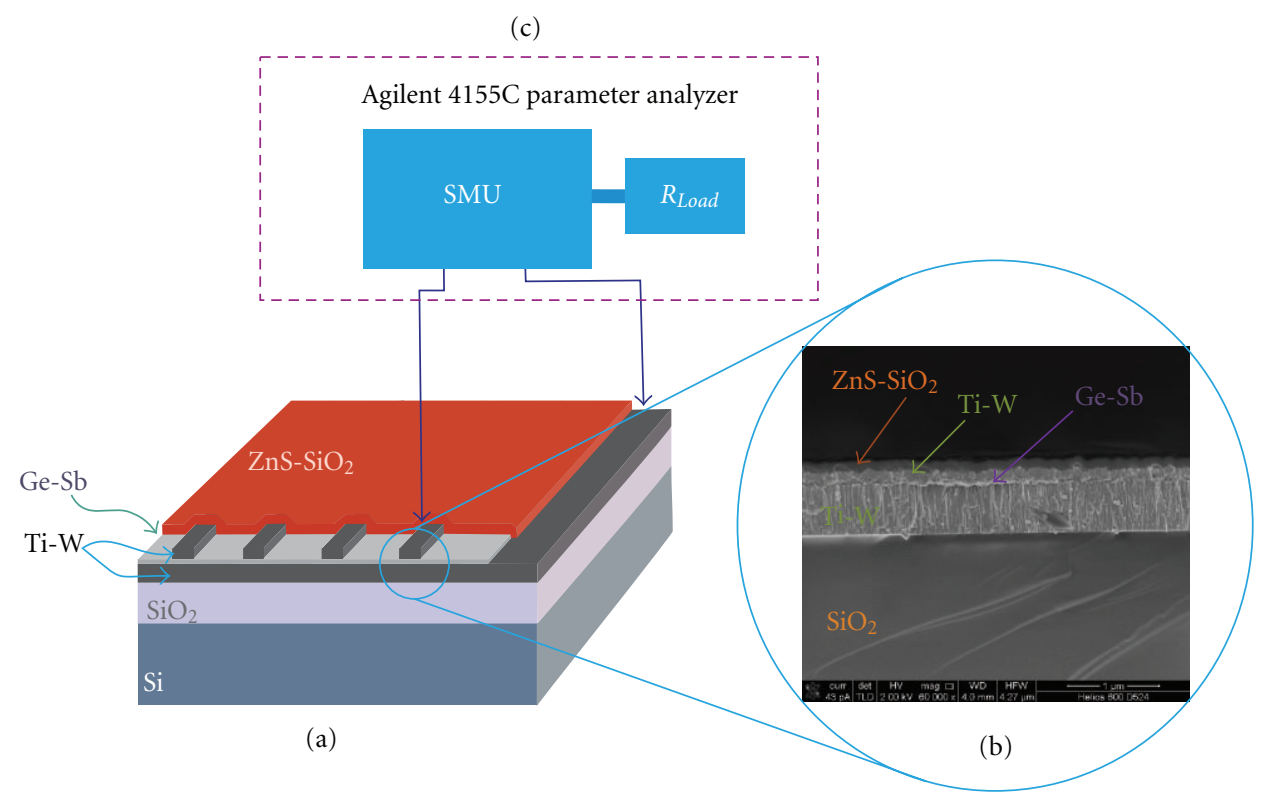

Figure 2: (a) A diagram of the Ge-Sb thin film phase-change memory device fabricated in this work, (b) SEM image of the fabricated Ge-Sb thin film device, (c) setup for electrical characterization of Ge-Sb thin film device.

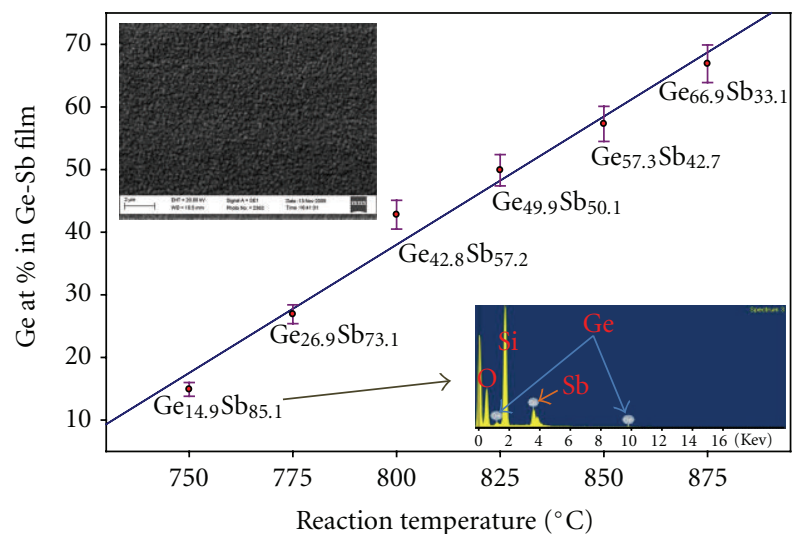

Figure 3: Compositions of CVD-grown Ge-Sb thin films measured by EDX technique and a typical SEM micrograph of Ge-Sb thin film deposited on $\mathrm{SiO}_{2} / \mathrm{Si}$ substrate (inset).

been applied to study the morphology of the Ge-Sb thin films. A typical SEM micrograph of the Ge-Sb thin film on $\mathrm{SiO}_{2} / \mathrm{Si}$ is shown in the inset of Figure 3. As shown, homogeneous $\mathrm{Ge}-\mathrm{Sb}$ thin films have been successfully fabricated by this CVD technique. In addition, by changing the substrate temperature (zone 2) from $150^{\circ} \mathrm{C}$ to $250^{\circ} \mathrm{C}$ and keeping the reaction temperature at $750^{\circ} \mathrm{C}$ (zone 1), crystallized eutectic $\mathrm{Ge}-\mathrm{Sb}$ thin film can be formed as shown in Figure 4(a). The thickness of the film determined by the edge profile of cleaved sample (Figure 4(b)) revealed that the deposition rate was about $2 \mathrm{~nm} / \mathrm{min}$. The grain sizes of the $100 \mathrm{~nm}$ thick crystallized Ge-Sb thin film were in the range of $80-100 \mathrm{~nm}$. In addition, the surface roughness of the Ge$\mathrm{Sb}$ thin films was further improved by using rapid thermal annealing at $600^{\circ} \mathrm{C}$ for 30 seconds. This postdeposition annealing at $600^{\circ} \mathrm{C}$ has significantly improved the surface roughness as the melting point of eutectic $\mathrm{Ge}-\mathrm{Sb}$ is about $590^{\circ} \mathrm{C}$ which means a melt-quenching process has been carried out [21]. Energy dispersive X-ray (EDX) analysis has been applied to determine the composition of $\mathrm{Ge}-\mathrm{Sb}$ thin films, and the results are shown in Figure 3. In the result shown, a composition with $14.9 \% \mathrm{Ge}$, very close to the eutectic composition of $\mathrm{Ge}_{15} \mathrm{Sb}_{85}$ binary system, was obtained. This film was processed with the reaction temperature at $750^{\circ} \mathrm{C}$ and flow rates of $\mathrm{GeCl}_{4}, \mathrm{SbCl}_{5}$, and $6 \% \mathrm{H}_{2} / \mathrm{Ar}$ of $50 \mathrm{~mL} / \mathrm{min}, 150 \mathrm{~mL} / \mathrm{min}$, and $200 \mathrm{~mL} / \mathrm{min}$, respectively. The EDX spectrum shown in Figure 3 confirms that the higher the temperature of the CVD reaction, the greater the content of germanium found in the $\mathrm{Ge}-\mathrm{Sb}$ thin film. The EDX spectrum also reveals that unreacted $\mathrm{Cl}$ was not detected in the CVD-grown $\mathrm{Ge}-\mathrm{Sb}$ thin film which suggested the high-purity Ge-Sb thin films have been fabricated because the detection limit of $\mathrm{Cl}$ using $\mathrm{EDX}$ technique is about $0.1 \mathrm{wt} \%$ [22].

We used micro-Raman to characterize the composition and phase structure of CVD-grown Ge-Sb thin films. The micro-Raman used was a RENISHAW Ramascope which is equipped with a CCD camera. A $633 \mathrm{~nm}$ He-Ne laser was used to excite the sample, and the Raman shift spectrum was measured from $380 \mathrm{~cm}^{-1}$ to $100 \mathrm{~cm}^{-1}$ with a resolution of $1 \mathrm{~cm}^{-1}$. These Raman spectra are shown in Figure 5(a). The Raman shift peaks of Ge-Sb were found at around $260 \mathrm{~cm}^{-1}$ (LO mode) with a shoulder peak at about $220 \mathrm{~cm}^{-1}$ (TO mode). In addition, a small Sb-Sb peak was found at about $200 \mathrm{~cm}^{-1}$ and $\mathrm{Ge}-\mathrm{Ge}$ peak was found at about $290 \mathrm{~cm}^{-1}$. The Raman analysis results of CVD-grown Ge-Sb thin films agree with those reported in [23]. It should be noted that the Ge-Ge peak was larger when the Ge atomic ratio increased in Ge-Sb composition as shown in Figure 5(a). From the 


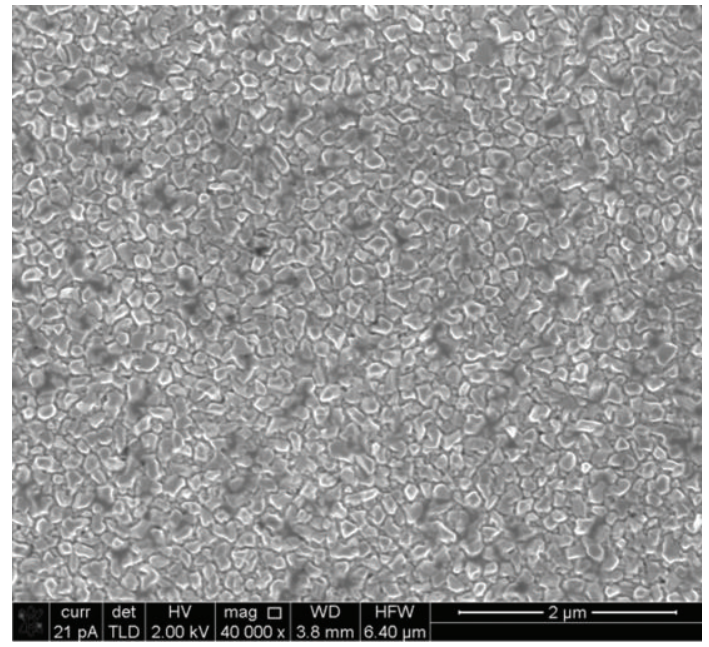

(a)

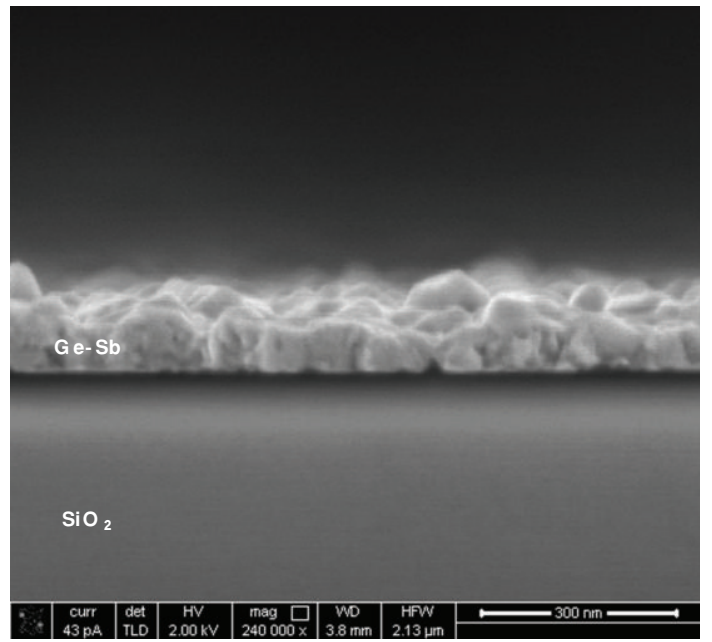

(b)

FIGURE 4: (a) SEM image of crystallized eutectic of Ge-Sb alloy thin films deposited $\mathrm{SiO}_{2} / \mathrm{Si}$ substrate. (b) SEM cross-sectional image of $100 \mathrm{~nm}$ thick crystalline Ge-Sb thin film deposited on $\mathrm{SiO}_{2} / \mathrm{Si}$ substrate.

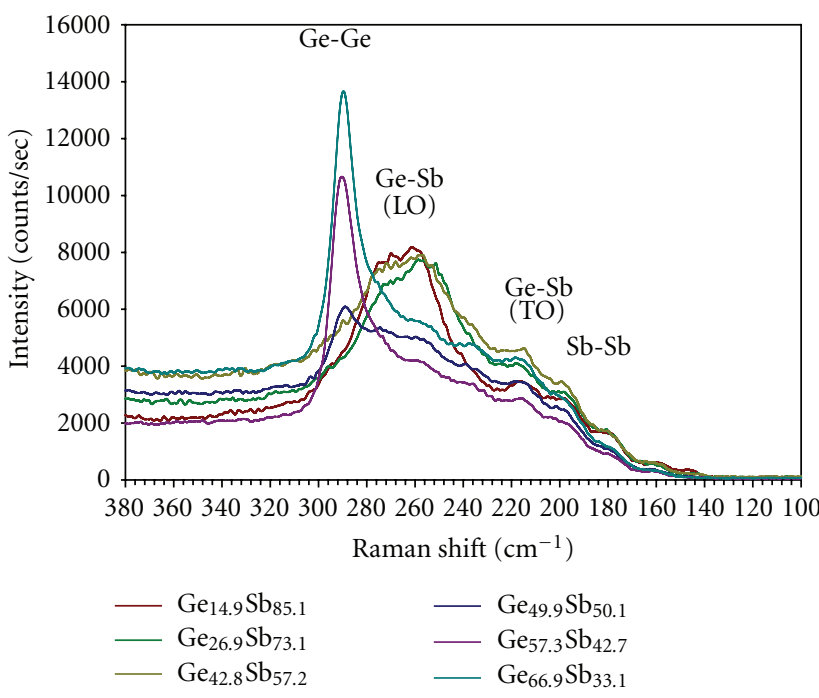

(a)

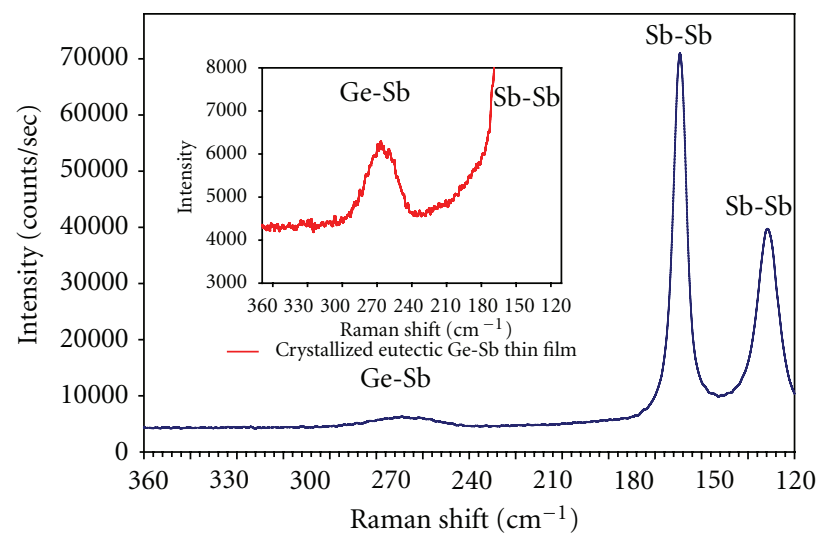

— Crystallized eutectic Ge-Sb thin film

Figure 5: (a) Raman spectra of Ge-Sb alloy thin films deposited on borosilicate glass substrates at the reaction temperatures ranging from $750^{\circ} \mathrm{C}$ to $875^{\circ} \mathrm{C}$. (b) Raman spectrum of crystallized eutectic Ge-Sb thin film.

Raman analysis of CVD-grown Ge-Sb thin films, Ge-Sb bonding has been revealed with $\mathrm{Ge}-\mathrm{Ge}$ bonding and $\mathrm{Sb}-\mathrm{Sb}$ bonding coexisted in the thin film formation. In addition, the amorphous phase of CVD-grown Ge-Sb thin film has also been confirmed as the crystalline Sb-Sb peak $\left(\sim 110 \mathrm{~cm}^{-1}\right)$ was not found in the Raman shift spectra. In addition, the Raman characteristics of the crystallized eutectic Ge-Sb thin film shown in Figure 5(b) reveals that strong Sb-Sb peaks are found at about $150 \mathrm{~cm}^{-1}$ and $110 \mathrm{~cm}^{-1}$ which did not appear in Raman spectra of the amorphous Ge-Sb thin films. These Raman results of crystallized Ge-Sb also agree with those in [24]. Nevertheless, the small Ge-Sb peak at about $260 \mathrm{~cm}^{-1}$ was also found in the crystallized eutectic Ge-Sb thin film.
The X-ray diffraction (XRD) technique was used to investigate the structure of the Ge-Sb thin films. The typical XRD result of amorphous Ge-Sb film is shown in Figure 6 (bottom), whereas the XRD pattern of crystallized CVDgrown $\mathrm{Ge}-\mathrm{Sb}$ film with eutectic composition is shown in Figure 6 (top) which matches with that of pure $\mathrm{Sb}$ in hexagonal structure. With small concentration of Ge in Ge$\mathrm{Sb}$ alloy system, it has been known that Ge atoms occupy sites of Sb lattice and do not disturb the $\mathrm{Sb}$ structure [25].

The CVD technique offers improved film conformality, morphology, and compositional control and increased manufacturing throughput without creating surface damage. 


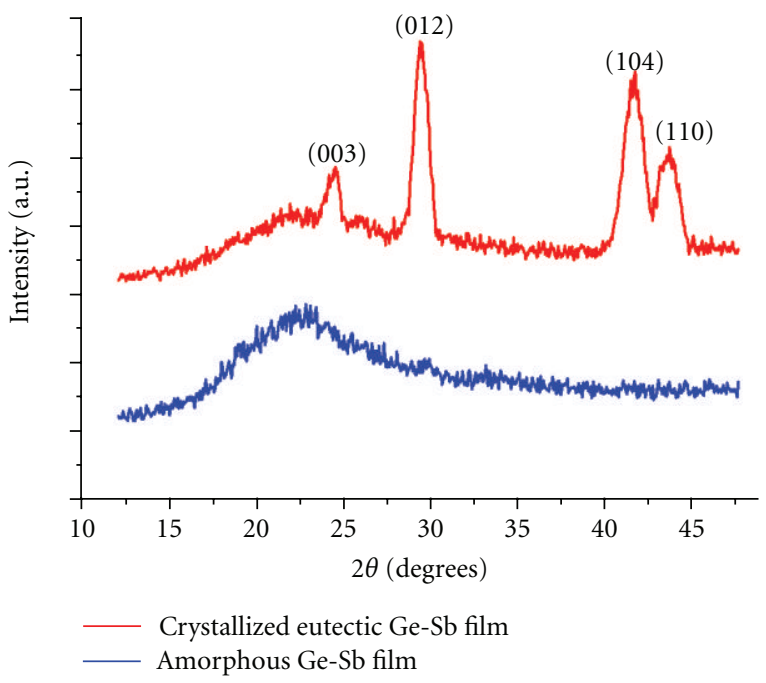

FIGURE 6: XRD results of typical amorphous Ge-Sb films (bottom) and crystallized eutectic Ge-Sb film (top).

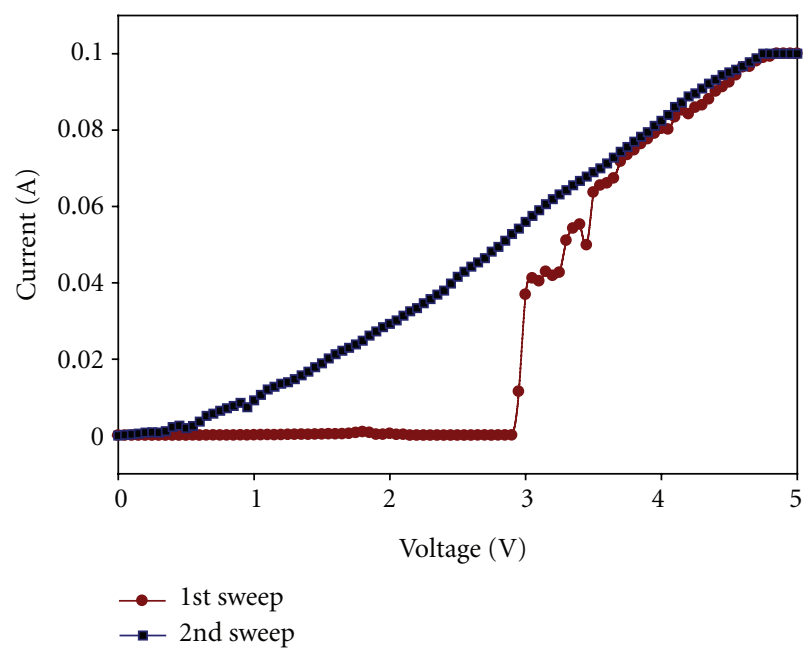

(a)

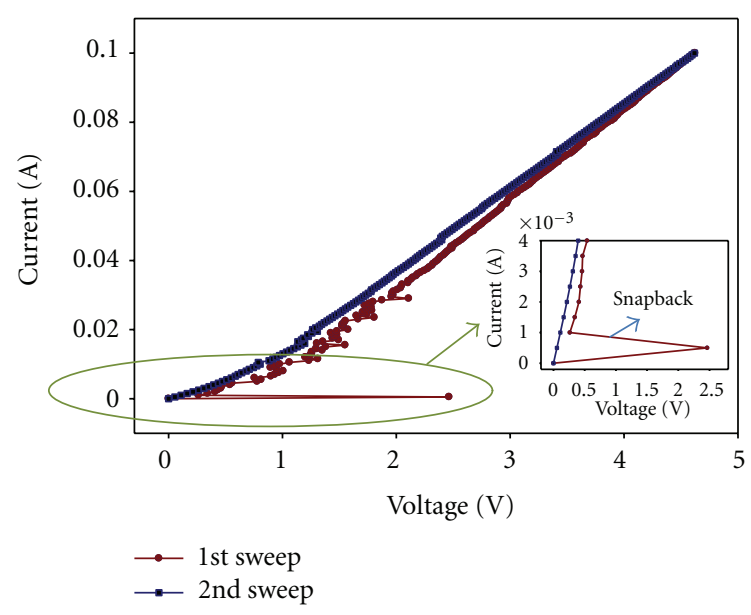

(b)

FIGURE 7: $I-V$ characteristics of the eutectic Ge-Sb thin film phase-change memory device (a) using a voltage sweeps whilst measuring the current (b) using a current sweep whilst measuring the voltage.

From the SEM images shown in Figure 4, we have demonstrated the good surface morphology and high compositional control of Ge-Sb thin films with this CVD process using metal chloride precursors. In comparison to the metalorganic CVD, our CVD system operated at atmospheric pressure rather than in the high vacuum chamber and high purity (99.9999\% pure) and lower costs of the precursors are the advantages of using our process. In addition, at the eutectic composition of $\mathrm{Ge}-\mathrm{Sb}$ material, the minimum melting temperature could be reached and there will be no phase separation during the melting process (amorphization) from the phase diagram of Ge-Sb binary system [21]. Since eutectic Ge-Sb potentially could be used in the ultrafast phase change switching memory application, we have designed and fabricated a prototype $\mathrm{Ge}-\mathrm{Sb}$ thin film phase change device for electrical characterization.
The electrical characterization of the previous Ge-Sb thin film device was carried out with the probe station setup consisting of an Agilent 4155C semiconductor parameter analyzer shown in Figure 2(c). By introducing a voltage sweep between 0 and $5 \mathrm{~V}$, the current across the fabricated cell was measured using the source measure unit within the semiconductor parameter analyzer. It should be noted that an internal load resistance within the instrument provides current limitation in order to protect the device. The $I$ $V$ characteristics of the eutectic Ge-Sb thin film device shown in Figure 7 were obtained using our experimental setup by using voltage sweeps and measuring the current (a) and a current sweep whilst measuring the voltage (b) and in each case this revealed three states of the film with a threshold of around 2.5-2.8 V. Starting at a high resistance state and applying the sweep, at the onset of the threshold, 
the material enters a lower resistivity regime which then gives way to the stable phase change (memory switching) by virtue of the Joule heating to above the crystallization point of the material. The resistance of the material in its noncrystalline state was $5.5 \times 10^{4} \Omega$, once the voltage was increased above the threshold, the resistance switches to a more conductive state showing a resistance of $29.4 \Omega$. The second sweep demonstrated that the changes were stable and the film was in a high conductivity low resistance state as a result of the first sweep. The electrical switching between amorphous and crystalline phases has been demonstrated and can be reproducible at least ten times. The resistance contrast between two phases was greater than $10^{3}$; therefore, this result would indicate promise for PCRAM applications.

In this paper, we have demonstrated an atmospheric pressure CVD process for the fabrication of Ge-Sb thin films with tuneable compositions. A phase change memory prototype device based on the CVD-grown Ge-Sb thin film has been fabricated, and the phase transition of this device has been demonstrated. These Te-free Ge-Sb films are promising for applications such as phase change memory and optical, electronic, and plasmonic switching [26]. We are now working on further characterizations of these Ge$\mathrm{Sb}$ films and developing nanoscale devices based on these materials.

\section{Conclusion}

Ge-Sb alloy thin films deposited on $\mathrm{SiO}_{2} / \mathrm{Si}$, borosilicate glass, and quartz glass substrates have been successfully fabricated by atmospheric pressure CVD using metal chloride precursors. The Ge-Sb films have been characterized by micro-Raman, SEM, EDX, and XRD techniques. The composition of Ge-Sb thin films can be varied by changing the reaction temperatures. A prototype $\mathrm{Ge}-\mathrm{Sb}$ thin film phase-change memory device has been fabricated and reversible threshold and phase change switching demonstrated electrically, with a threshold voltage of 2.2$2.5 \mathrm{~V}$. Currently, we are working on further characterization and device fabrication using these Ge-Sb thin films for phase-change memory and plasmonic switching device applications. The growth of phase-change materials into nanoelectronic devices is very essential, and our CVD process has demonstrated the potential solution for this application.

\section{Acknowledgments}

The authors would like to acknowledge the technical assistance of Mr. John Tucknott, Mr. Neil Fagan, Ed Weatherby Esq., Mr. Mark Lessey, and Mr. Trevor Austin. The authors also would like to acknowledge Dr. Mark E. Light for assistance in the XRD analysis. This work was funded by the Engineering Physical Sciences Research Council through our EPSRC Centre for Innovative Manufacturing in Photonics (Grant EP/C515668/1).

\section{References}

[1] M. H. R. Lankhorst, B. W. S. M. M. Ketelaars, and R. A. M. Wolters, "Low-cost and nanoscale non-volatile memory concept for future silicon chips," Nature Materials, vol. 4, no. 4, pp. 347-352, 2005.

[2] C. W. Jeong, S. J. Ahn, Y. N. Hwang et al., "Highly reliable ringtype contact for high-density phase change memory," Japanese Journal of Applied Physics, vol. 45, no. 4B, pp. 3233-3237, 2006.

[3] A. Pirovano, A. L. Lacaita, A. Benvenuti, F. Pellizzer, and R. Bez, "Electronic switching in phase-change memories," IEEE Transactions on Electron Devices, vol. 51, no. 3, pp. 452-459, 2004.

[4] R.-Y. Kim, H.-G. Kim, and S.-G. Yoon, "Structural properties of $\mathrm{Ge}_{2} \mathrm{Sb}_{2} \mathrm{Te}_{5}$ thin films by metal organic chemical vapor deposition for phase change memory applications," Applied Physics Letters, vol. 89, no. 10, Article ID 102107, 2006.

[5] M. Ritala, V. Pore, T. Hatanpää et al., "Atomic layer deposition of $\mathrm{Ge}_{2} \mathrm{Sb}_{2} \mathrm{Te}_{5}$ thin films," Microelectronic Engineering, vol. 86, no. 7-9, pp. 1946-1949, 2009.

[6] G. W. Burr, M. J. Breitwisch, M. Franceschini et al., "Phase change memory technology," Journal of Vacuum Science and Technology B, vol. 28, no. 2, pp. 223-262, 2010.

[7] R. A. Cobley and C. D. Wright, "Parameterized SPICE model for a phase-change RAM device," IEEE Transactions on Electron Devices, vol. 53, no. 1, pp. 112-117, 2006.

[8] Y. S. Park, K. J. Choi, N. Y. Lee et al., "Writing current reduction in phase change memory device with U-shaped heater (PCM-U)," Japanese Journal of Applied Physics, vol. 45, no. 2023, pp. L516-L518, 2006.

[9] C. N. Afonso, J. Solis, F. Catalina, and C. Kalpouzos, "Ultrafast reversible phase change in GeSb films for erasable optical storage," Applied Physics Letters, vol. 60, no. 25, pp. 3123-3125, 1992.

[10] J. Solis and C. N. Afonso, "Ultrashort-laser-pulse-driven rewritable phase-change optical recording in Sb-based films," Applied Physics A, vol. 76, no. 3, pp. 331-338, 2003.

[11] L. Van Pieterson, M. Van Schijndel, J. C. N. Rijpers, and M. Kaiser, "Te-free, Sb-based phase-change materials for highspeed rewritable optical recording," Applied Physics Letters, vol. 83, no. 7, pp. 1373-1375, 2003.

[12] L. Van Pieterson, M. H. R. Lankhorst, M. Van Schijndel, A. E. T. Kuiper, and J. H. J. Roosen, "Phase-change recording materials with a growth-dominated crystallization mechanism: a materials overview," Journal of Applied Physics, vol. 97, no. 8, Article ID 083520, 7 pages, 2005.

[13] L. Van Pieterson, E. W. Hesselink, J. C. N. Rijpers, M. Kaiser, M. A. Verheijen, and R. Elfrink, "Archival-overwrite performance of GeSnSb-based phase-change discs," Journal of Applied Physics, vol. 99, no. 6, Article ID 066111, 2006.

[14] T. J. Park, D. H. Kim, S. J. Park et al., "Phase transition characteristics and nonvolatile memory device performance of ZnxSb100-x alloys," Japanese Journal of Applied Physics, vol. 46, no. 20-24, pp. L543-L545, 2007.

[15] Y. C. Chen, C. T. Rettner, S. Raoux et al., "Ultra-thin phasechange bridge memory device using GeSb," in Proceedings of the International Electron Devices Meeting (IEDM '06), San Francisco, Calif, USA, December 2006.

[16] C. Cabral Jr., L. Krusin-Elbaum, J. Bruley et al., "Direct evidence for abrupt postcrystallization germanium precipitation in thin phase-change films of Sb-15 at. \% Ge," Applied Physics Letters, vol. 93, no. 7, Article ID 071906, 3 pages, 2008.

[17] J.-H. Kim, K. Lee, S.-J. Chae et al., "Change in the resistivity of $\mathrm{Ge}$-doped $\mathrm{Sb}$ phase change thin films grown by chemical 
vapor deposition according to their microstructures," Applied Physics Letters, vol. 94, no. 22, Article ID 222115, 2009.

[18] C. C. Huang and D. W. Hewak, "High-purity germaniumsulphide glass for optoelectronic applications synthesised by chemical vapour deposition," Electronics Letters, vol. 40, no. 14, pp. 863-865, 2004.

[19] C. C. Huang, D. W. Hewak, and J. V. Badding, "Deposition and characterization of germanium sulphide glass planar waveguides," Optics Express, vol. 12, no. 11, pp. 2501-2506, 2004.

[20] C. C. Huang, K. Knight, and D. W. Hewak, "Antimony germanium sulphide amorphous thin films fabricated by chemical vapour deposition," Optical Materials, vol. 29, no. 11, pp. 1344-1347, 2007.

[21] ASM international Alloy Phase Diagram and Handbook Committees, Alloy Phase Diagrams, vol. 3 of ASM Handbook, ASM International, 1992.

[22] P. Kuisma-Kursula, "Scanning electron microscopy-energy dispersive spectrometry and proton induced $\mathrm{x}$-ray emission analyses of medieval glass from Koroinen (Finland)," Archaeometry, vol. 41, no. 1, pp. 71-79, 1999.

[23] A. Kobayashi, K. E. Newman, and J. D. Dow, "Densities of phonon states for $(\mathrm{GaSb})_{1-x}\left(\mathrm{Ge}_{2}\right)_{x}$," Physical Review B, vol. 32, no. 8, pp. 5312-5327, 1985.

[24] A. Roy, M. Komatsu, K. Matsuishi, and S. Onari, "Raman spectroscopic studies on $\mathrm{Sb}$ nanoparticles in $\mathrm{SiO}_{2}$ matrix prepared by rf-cosputtering technique," Journal of Physics and Chemistry of Solids, vol. 58, no. 5, pp. 741-747, 1997.

[25] Y. Jung, C. Y. Yang, S. H. Lee, and R. Agarwal, "Phase-Change ge-sb nanowires: synthesis, memory switching, and phaseinstability," Nano Letters, vol. 9, no. 5, pp. 2103-2108, 2009.

[26] Z. L. Sámson, K. F. MacDonald, F. De Angelis et al., "Metamaterial electro-optic switch of nanoscale thickness," Applied Physics Letters, vol. 96, no. 14, Article ID 143105, 2010. 

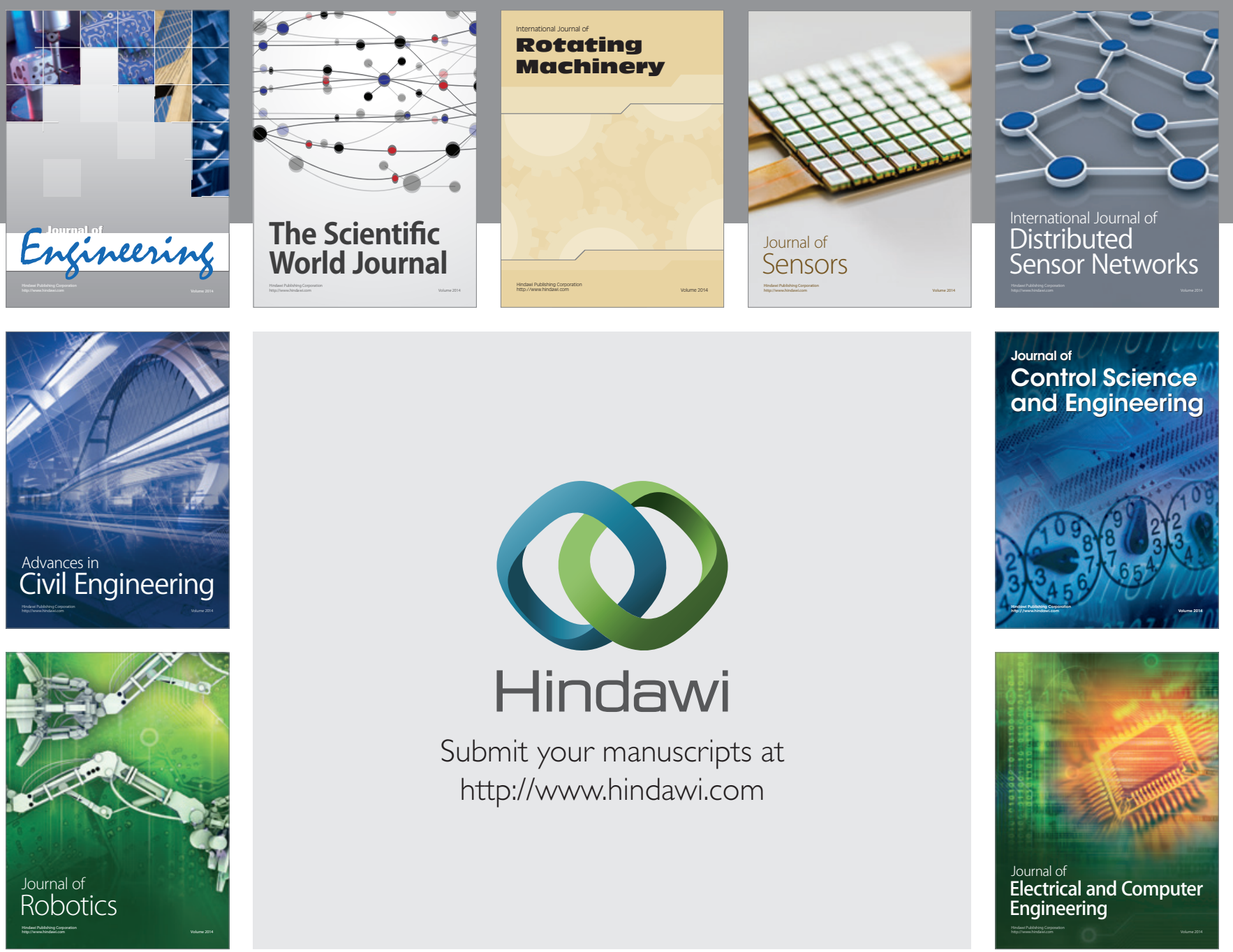

Submit your manuscripts at

http://www.hindawi.com
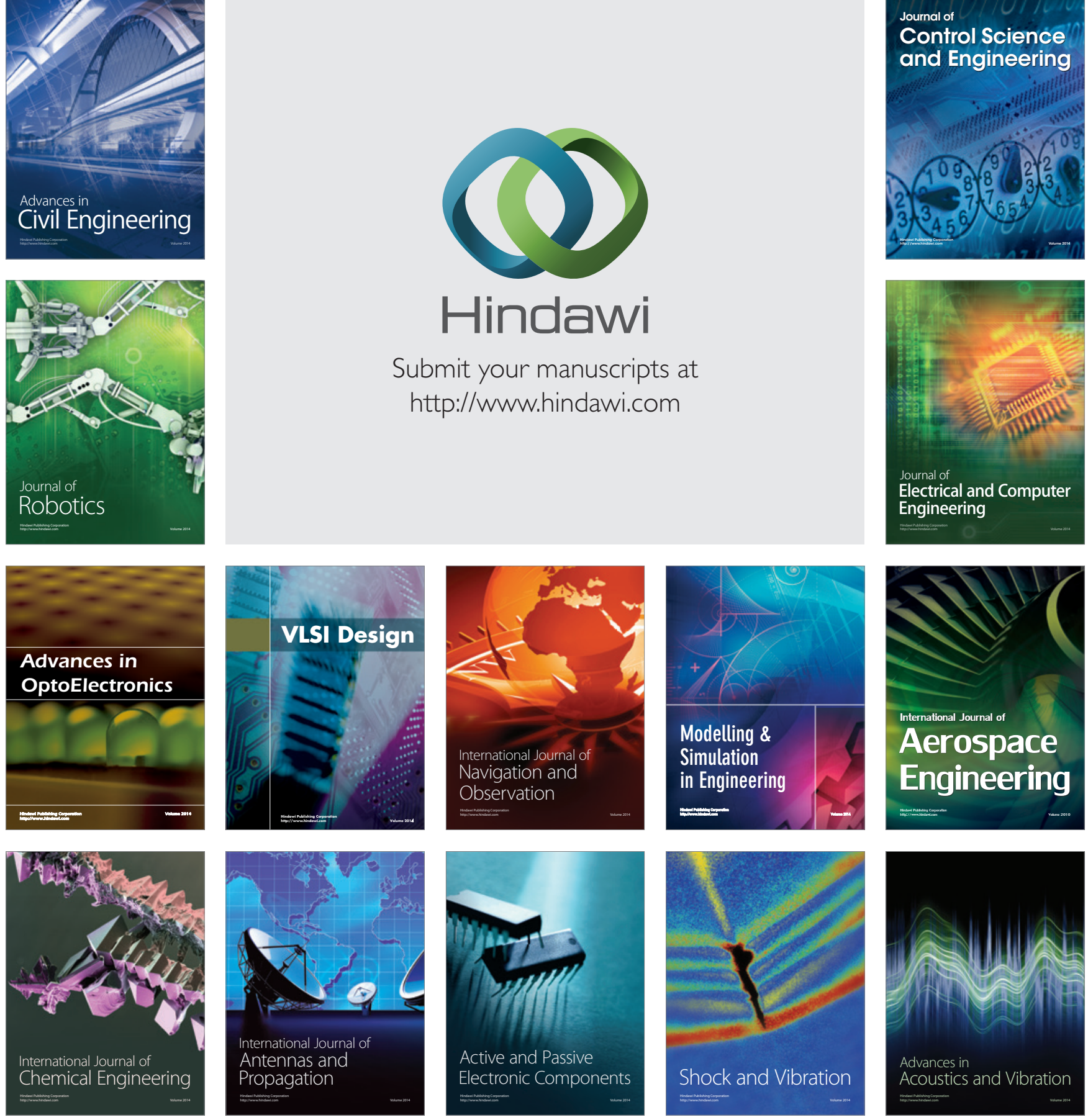